\title{
Androgen receptor gene polymorphism influence fat accumulation: A longitudinal study from adolescence to adult age
}

\author{
J. G. Ponce-González ${ }^{1,2}$, L. Rodríguez-Garcia ${ }^{1,2}$, J. Losa-Reyna ${ }^{1,2}$, A. Guadalupe-Grau ${ }^{1,2}$, F. G. Rodriguez-Gonzalez ${ }^{3,4}$, \\ B. N. Díaz-Chico ${ }^{3,4}$, C. Dorado ${ }^{1,2}$, J. A. Serrano-Sanchez ${ }^{1,2}$, J. A. L. Calbet ${ }^{1,2}$ \\ ${ }^{1}$ Department of Physical Education, University of Las Palmas de Gran Canaria, Las Palmas de Gran Canaria, Spain, ${ }^{2}$ Research \\ Institute of Biomedical and Health Sciences, University of Las Palmas de Gran Canaria, Las Palmas de Gran Canaria, Spain, \\ ${ }^{3}$ Department of Biochemistry and Physiology, Universidad de Las Palmas de Gran Canaria, Las Palmas de Gran Canaria, Spain, \\ ${ }^{4}$ Canary Islands Cancer Research Institute (ICIC), University of Las Palmas de Gran Canaria, Las Palmas de Gran Canaria, Spain \\ Corresponding author: Jose A. L. Calbet, Departamento de Educación Física, Campus Universitario de Tafira, 35017 Las Palmas de \\ Gran Canaria, Canary Islands, Spain. Tel: 0034928458 896, Fax: 0034928 458 867, E-mail: lopezcalbet@gmail.com
}

Accepted for publication 20 September 2015

To determine the influence of androgen receptor CAG and GGN repeat polymorphisms on fat mass and maximal fat oxidation (MFO), CAG and GGN repeat lengths were measured in 128 young boys, from which longitudinal data were obtained in 45 of them [mean \pm SD: $12.8 \pm 3.6$ years old at recruitment, and $27.0 \pm 4.8$ years old at adult age]. Subjects were grouped as CAG short $\left(\mathrm{CAG}_{\mathrm{S}}\right)$ if harboring repeat lengths $\leq \mathbf{2 1}$, the rest as CAG long $\left(\mathrm{CAG}_{\mathrm{L}}\right)$; and GGN short $\left(\mathrm{GGN}_{\mathrm{S}}\right)$ if GGN repeat lengths $\leq 23$, or long if $>23\left(G_{G}\right)$. CAG and GGN $_{S}$ were associated with lower adiposity than $\mathrm{CAG}_{\mathrm{L}}$ or $\mathrm{GGN}_{\mathrm{L}}(P<\mathbf{0 . 0 5})$. There was an association between the logarithm of CAG repeats polymorphism and the changes of body mass $(r=0.34, P=0.03)$. At adult age, $\mathrm{CAG}_{\mathrm{s}}$ men showed lower accumulation of total body and trunk fat mass, and lower resting metabolic rate (RMR) and MFO per $\mathrm{kg}$ of total lean mass compared with $\mathrm{CAG}_{\mathrm{L}}(P<0.05)$. GGN men also showed lower percentage of body fat $(P<0.05)$. In summary, androgen receptor CAG and GGN repeat polymorphisms are associated with RMR, MFO, fat mass, and its regional distribution in healthy male adolescents, influencing fat accumulation from adolescence to adult age.
Androgens regulate adipose tissue metabolism, fat mass accumulation, and lipid oxidation (Host et al., 2013; O'Reilly et al., 2014). Cells respond to androgens depending on the concentration to which they are exposed but also on the responsiveness of the androgen receptors (AR) (O'Reilly et al., 2014). The AR gene contains a polyglutamine tract encoded by $\mathrm{CAG}$ repeats and a polyglycine tract (GGN) encoded by $(\text { GGT })_{3}$ GGG $(\text { GGT })_{2}(\text { GGC })_{n}$ that could influence its activity. In that sense, the length of CAG repeats and AR transactivation potential is inversely correlated (Chamberlain et al., 1994; Kazemi-Esfarjani et al., 1995; Beilin et al., 2000). Although GGN polymorphism has been less studied than CAG polymorphism, a short GGN is associated with greater androgenic activity in cell cultures (Ding et al., 2005). The androgenic effects of pharmacotherapy with testosterone analogues depend on the CAG repeat length in hypogonadal men (Zitzmann, 2009). Moreover, androgen receptor CAG and GGN repeat length polymorphisms are associated with fat and lean mass in adult humans (Gustafson et al., 2003; Walsh et al., 2005; Stanworth et al., 2008; Nielsen et al., 2010; Ponce-González et al., 2012). However, little is known about the influence of AR CAG polymorphism on body composition changes during growth in children and adolescents, while the potential influence of AR GGN polymorphism remains unknown.

Cross-sectional studies have reported an inverse relationship between the AR CAG repeat length and height in prepubertal boys. This association, however, disappeared during puberty in two comparable cohorts of 226 (age 12.9-36 years) and 244 subjects (age 8-14 years), respectively (Voorhoeve et al., 2011). Moreover, no associations were found between AR CAG repeat length and body composition in this study (Voorhoeve et al., 2011). This is in contrast with a positive association between CAG length and skinfold thickness between 10 and 12 years of age which was observed in a cohort of 78 healthy Danish boys (age 6.2-12.4 years) (Mouritsen et al., 2013).

Therefore, the main aim of this study was to determine whether AR CAG and GGN repeat polymorphisms may be associated with the changes in body composition from adolescence to adult age. Another aim was to investigate whether AR polymorphisms are associated to the maximal fat oxidation capacity in men and how this could influence the accumulation of fat mass during growth. 


\section{Ponce-González et al.}

We hypothesized that androgen sensitivity, indicated by the length of CAG and GGN repeats in the $\mathrm{X}$-chromosomal androgen receptor (AR) gene, determines the level of fat and lean mass at young age, and the longitudinal changes from puberty to the adult age.

\section{Methods}

Subjects

Initially, this cohort included 128 young boys from Gran Canaria (Spain), from which longitudinal data were obtained in 45 subjects. The recruitment started in February 1998 while the second assessment was obtained in January 2013. All subjects underwent a medical examination. Inclusion criteria were: age ranging from 8 to $<17$ years at recruitment. Subjects smoking, taking any kind of medications, or having any chronic disease, hypertension, or orthopedic limitations were excluded. The study was performed in accordance with the Helsinki Declaration of 1975 as regards the conduct of clinical research, being approved by the Ethical Committee of the University of Las Palmas de Gran Canaria. After receiving written and verbal information on the potential risk and benefits of the study, all subjects and parents signed a consent form to participate in this study. No additional tests were performed between the first and the second assessments.

\section{Tests}

Boys reported to the laboratory between 07:30 and 08:30 h, under fasting overnight conditions. After saliva collection, the International Physical Activity Questionnaire (IPAQ) was applied and a Tanner stage self-assessed as previously reported (Vicente-Rodriguez et al., 2004; Roman-Viñas et al., 2010). Then, their body composition was measured by dual-energy X-ray absorptiometry (DXA). This was followed by the assessment of physical fitness $\left(\mathrm{VO}_{2 \max }\right)$ as previously reported (Guadalupe-Grau et al., 2011).

Approximately 14 years later, subjects reported to the laboratory after an overnight fast for assessment of their body composition (same DXA analyzer) followed by measurement of their resting metabolic rate (RMR), maximal fat oxidation (MFO) capacity, and $\mathrm{VO}_{2 \max }$ with indirect calorimetry. Subjects were requested to refrain from non-habitual exercise, caffeine, or alcohol drinks for at least $24 \mathrm{~h}$ prior to the test.

\section{Body composition}

Whole body composition was assessed by DXA (QDR-1500, Hologic Corp., Software version 7.10, Waltham, Massachusetts, USA) (Perez-Gomez et al., 2008). Upper and lower limb lean mass $(\mathrm{kg})$ was calculated from the regional analysis of the whole body scan, which gives a valid and reliable estimate of muscle mass in the extremities (Kim et al., 2002).

\section{Indirect calorimetry}

After overnight fast, RMR was measured during $30 \mathrm{~min}$ while subjects lied supine on a bed using a metabolic cart (Vmax N29; Sensormedics, Yorba Linda, California, USA). This was followed by an incremental exercise test to determine the maximal fat oxidation (MFO), and the intensity at which MFO occurred (FatMax) during leg cycling (Achten et al., 2002). The test started at $30 \mathrm{~W}$ for $5 \mathrm{~min}$, followed by $30 \mathrm{~W}$ increments every $3 \mathrm{~min}$. When subjects reached a RER > 1.0, the exercise was stopped at the end of the corresponding $3 \mathrm{~min}$ period load. After $5 \mathrm{~min}$ of recovery, an incremental test $(30 \mathrm{~W} / \mathrm{min}$ ) beginning in the last load of the MFO test was performed to determine $\mathrm{VO}_{2 \max }$. Subjects were instructed to maintain a pedaling rate of $80 \mathrm{rpm}$. Fat and carbohydrate oxidation was calculated from $\mathrm{VO}_{2}$ and $\mathrm{VCO}_{2}$ values during the last $60 \mathrm{~s}$ of each exercise step in the graded exercise tests, using standard indirect calorimetry equations (Frayn, 1983). It was assumed that protein oxidation was similar and small during the incremental exercise tests.

\section{CAG and GGN repeat polymorphisms}

CAG and GGN repeat polymorphisms were determined as previously reported (Ponce-González et al., 2012). Briefly, DNA was extracted from saliva samples $(200 \mu \mathrm{L})$ using High Pure PCR Template Preparation Kits (Roche Applied Science, Mannheim, Germany). To determine the length of the CAG and GGN repeats the corresponding regions located on the exon 1 of the AR gene (Genbank accession no. M27423) were amplified using two pairs of primers whose sequences have been previously reported (Ponce-González et al., 2012). Fragment separation was performed by automáted capillary electrophoresis, using an ABI Prism 3100 Genetic Analyzer (Applied Biosystems, Foster City, California, USA) and the length was determined with Gene Scan Analysis Software (version 3.7) (Applied Biosystems). Internal standards supplied by the manufacturer were used for quality control.

\section{Statistical analysis}

Taken into account that the coefficient of variation for the assessment of whole body fat mass is close to $3 \%$, the minimum sample size required to demonstrate a $3 \%$ difference in fat mass was nine subjects per group for an $\alpha=0.05$ and $\beta=0.8$. All variables were checked for normal distribution using the test of Shapiro-Wilk. When necessary, the analysis was done on logarithmically transformed data. The influence of CAG and GGN repeat lengths on body composition, RMR, MFO, and $\mathrm{VO}_{2 \max }$ was determined taking CAG and GGN repeat lengths as either continuous or as dichotomous variables with allele cut-off thresholds. The median value that resulted in the most balanced grouping was used as a cutoff threshold (Hickey et al., 2002; Rodriguez-Gonzalez et al., 2009). The $\mathrm{CAG}$ and GGN number distributions were $\mathrm{CAG}_{S}$ (short $\leq 21$ repeats; $n=24), \mathrm{CAG}_{\mathrm{L}}$ (long $>21$ repeats; $n=21$ ), $\mathrm{GGN}_{\mathrm{S}}$ (short $\leq 23$ repeats; $n=30$ ), and $\mathrm{GGN}_{\mathrm{L}}$ (long $\geq 24$ repeats; $n=15$ ). The relationship between CAG and GGN as continuous variables with body composition, and physical fitness variables was examined using linear regression analysis. Comparisons between short and long groups were carried out with analysis of variance (ANOVA) after accounting for age, height, total lean body mass, Tanner, and $\mathrm{VO}_{2 \max }$ as covariates. Separate analyses were performed introducing these covariates in single steps, separately, or in combination. This allows to determine the specific influence of each covariate separately or of each combination of covariates. The homogeneity of variance was determined with the Levene test. When it was necessary, lean mass was corrected for differences in height by dividing muscle mass by height ${ }^{2}$ (Lietzke, 1956). To rule out the possibility of a selection bias, CAG and GGN lengths were compared between the subjects remaining in the cohort and those lost or excluded, using one-way ANOVA. Additional comparisons were carried out to determine whether the subjects remaining in the cohort had similar body composition and fitness levels at recruitment compared with the subjects that were lost or excluded from the second assessment, using ANOVA after accounting for age, height, and Tanner stage as covariates.

\section{Results}

Subjects' characteristics, body composition, and physical fitness at young and adult age for the CAG and GGN 
Androgen receptor polymorphism and fat mass

Table 1. Subjects' characteristics, body composition, and physical fitness at young and adult age for short and long CAG groups

\begin{tabular}{|c|c|c|c|c|c|c|c|c|}
\hline & \multicolumn{4}{|c|}{ Young age } & \multicolumn{4}{|c|}{ Adult age } \\
\hline & $\mathrm{CAG}_{S}$ & $n$ & $C A G_{L}$ & $n$ & $\mathrm{CAG}_{\mathrm{S}}$ & $n$ & $C A G_{L}$ & $n$ \\
\hline Age & $13.4 \pm 3.8$ & 24 & $12.1 \pm 3.4$ & 21 & $27.2 \pm 4.3$ & 24 & $26.1 \pm 3.7$ & 21 \\
\hline Height (cm) & $156.9 \pm 17.8$ & 24 & $153.1 \pm 17.6$ & 21 & $178.2 \pm 7.1$ & 24 & $179.8 \pm 7.5$ & 21 \\
\hline Body mass $(\mathrm{kg})$ & $48.0 \pm 15.1$ & 24 & $51.3 \pm 18.4$ & 21 & $73.8 \pm 12.4$ & 24 & $89.9 \pm 19.0^{*}$ & 21 \\
\hline Body mass index (BMI) & $18.9 \pm 3.0$ & 24 & $21.2 \pm 4.2^{\star}$ & 21 & $23.2 \pm 3.6$ & 24 & $27.8 \pm 5.4^{*}$ & 21 \\
\hline Percentage of body fat (\%) & $19.0 \pm 9.3$ & 24 & $25.7 \pm 10.9^{\star}$ & 21 & $19.2 \pm 10.0$ & 23 & $22.7 \pm 9.8^{\dagger}$ & 19 \\
\hline Fat mass in the trunk region $(\mathrm{kg})$ & $2.8 \pm 2.6$ & 24 & $4.9 \pm 3.4^{\star}$ & 21 & $6.8 \pm 5.7$ & 23 & $11.0 \pm 8.2^{*}$ & 19 \\
\hline Body fat mass $(\mathrm{kg})$ & $9.2 \pm 6.1$ & 24 & $12.9 \pm 6.9^{\star}$ & 21 & $14.9 \pm 9.6$ & 23 & $21.8 \pm 13.6^{\star}$ & 19 \\
\hline Lean body mass (kg) & $36.3 \pm 12.3$ & 24 & $35.8 \pm 14.7^{\ddagger}$ & 21 & $55.7 \pm 6.4$ & 23 & $64.5 \pm 8.7^{\star}$ & 19 \\
\hline Lean mass arms (kg) & $3.5 \pm 1.4$ & 24 & $3.5 \pm 1.8^{\ddagger}$ & 21 & $6.4 \pm 1.1$ & 23 & $7.9 \pm 1.5^{\star}$ & 19 \\
\hline Lean mass legs $(\mathrm{kg})$ & $12.3 \pm 4.7$ & 24 & $12.3 \pm 5.7^{\ddagger}$ & 21 & $18.2 \pm 2.3$ & 23 & $20.9 \pm 3.3^{*}$ & 19 \\
\hline Lean mass extremities (kg) & $15.9 \pm 6.1$ & 24 & $15.8 \pm 7.5^{\ddagger}$ & 21 & $24.7 \pm 3.1$ & 23 & $28.8 \pm 4.5^{\star}$ & 19 \\
\hline \multicolumn{9}{|l|}{ Maximal aerobic power } \\
\hline $\mathrm{VO}_{2 \max }(\mathrm{mL} / \mathrm{min})$ & $2.2 \pm 0.8$ & 24 & $2.3 \pm 0.8$ & 18 & $3.1 \pm 0.6$ & 24 & $3.8 \pm 0.5$ & 21 \\
\hline $\mathrm{VO}_{2 \max } /$ body mass $(\mathrm{mL} / \mathrm{kg} / \mathrm{min})$ & $47.9 \pm 8.4$ & 24 & $47.1 \pm 6.1$ & 18 & $42.6 \pm 7.7$ & 24 & $44.4 \pm 9.3$ & 21 \\
\hline $\mathrm{VO}_{2 \max } / \mathrm{LBM}(\mathrm{mL} / \mathrm{kg} / \mathrm{min})$ & $62.7 \pm 12.8$ & 24 & $66.8 \pm 9.3$ & 18 & $55.4 \pm 7.6$ & 23 & $59.8 \pm 8.3$ & 19 \\
\hline $\mathrm{VO}_{2 \max } / \mathrm{LML}(\mathrm{mL} / \mathrm{kg} / \mathrm{min})$ & $187.6 \pm 38.8$ & 24 & $199.8 \pm 36.2$ & 18 & $169.4 \pm 22.2$ & 23 & $185.2 \pm 28.1^{*}$ & 19 \\
\hline
\end{tabular}

Subjects were grouped as $C A G$ short $\left(C A G_{S}\right)$ if harboring repeat lengths of $\leq 21$ and $C A G$ long $\left(C A G_{L}\right)$ if harboring repeat lengths of $>21$. Body composition statistical analysis was done with logarithmic data.

${ }^{\star} P<0.05$ without adjusting for any variable.

${ }^{\dagger} P<0.05$ after accounting for $\mathrm{VO}_{2 \max }$.

$\ddagger P<0.05$ after adjusting for Tanner stage.

BMI, body mass index; LBM, lean body mass; LML, lean mass legs.

Table 2. Subjects' characteristics, body composition, and physical fitness at young and adult age for short and long GGN groups

\begin{tabular}{|c|c|c|c|c|c|c|c|c|}
\hline & \multicolumn{4}{|c|}{ Young age } & \multicolumn{4}{|c|}{ Adult age } \\
\hline & $\mathrm{GGN}_{\mathrm{S}}$ & $n$ & $\mathrm{GGN}_{\mathrm{L}}$ & $n$ & $\mathrm{GGN}_{S}$ & $n$ & $\mathrm{GGN}_{\mathrm{L}}$ & $n$ \\
\hline Age & $12.8 \pm 4.0$ & 30 & $13.0 \pm 3.1$ & 15 & $26.6 \pm 4.3$ & 30 & $26.8 \pm 3.4$ & 15 \\
\hline Height $(\mathrm{cm})$ & $153.6 \pm 18.4$ & 30 & $158.2 \pm 15.9$ & 15 & $178.7 \pm 7.4$ & 30 & $179.5 \pm 7.1$ & 15 \\
\hline Body mass $(\mathrm{kg})$ & $47.7 \pm 16.7$ & 30 & $53.1 \pm 16.3$ & 15 & $79.6 \pm 17.5$ & 30 & $84.7 \pm 17.9$ & 15 \\
\hline Body mass index (BMI) & $19.6 \pm 3.6$ & 30 & $20.8 \pm 4.0$ & 15 & $24.9 \pm 4.8$ & 30 & $26.3 \pm 5.4$ & 15 \\
\hline Percentage of body fat (\%) & $20.9 \pm 10.6$ & 30 & $24.5 \pm 10.4^{\dagger}$ & 15 & $19.4 \pm 9.8$ & 27 & $23.2 \pm 10.1^{*}$ & 15 \\
\hline Fat mass in the trunk region $(\mathrm{kg})$ & $3.3 \pm 2.8$ & 30 & $4.8 \pm 3.6^{\dagger}$ & 15 & $7.8 \pm 6.7$ & 27 & $10.3 \pm 7.8^{*}$ & 15 \\
\hline Body fat mass $(\mathrm{kg})$ & $9.9 \pm 6.4$ & 30 & $12.9 \pm 6.9^{\dagger}$ & 15 & $16.6 \pm 11.3$ & 27 & $20.6 \pm 13.1^{*}$ & 15 \\
\hline Lean body mass (kg) & $35.4 \pm 13.9$ & 30 & $37.5 \pm 12.5$ & 15 & $59.4 \pm 9.0$ & 27 & $60.1 \pm 8.1$ & 15 \\
\hline Lean mass arms (kg) & $3.4 \pm 1.6$ & 30 & $3.7 \pm 1.6$ & 15 & $7.0 \pm 1.4$ & 27 & $7.2 \pm 1.6$ & 15 \\
\hline Lean mass legs $(\mathrm{kg})$ & $12.0 \pm 5.3$ & 30 & $12.9 \pm 4.8$ & 15 & $19.5 \pm 3.3$ & 27 & $19.4 \pm 2.8$ & 15 \\
\hline Lean mass extremities $(\mathrm{kg})$ & $15.4 \pm 6.9$ & 30 & $16.6 \pm 6.2$ & 15 & $26.6 \pm 4.5$ & 27 & $26.5 \pm 4.0$ & 15 \\
\hline \multicolumn{9}{|l|}{ Maximal aerobic power } \\
\hline $\mathrm{VO}_{2 \max }(\mathrm{mL} / \mathrm{min})$ & $2.2 \pm 0.8$ & 29 & $2.4 \pm 0.7$ & 13 & $3.4 \pm 0.7$ & 30 & $3.5 \pm 0.6$ & 15 \\
\hline $\mathrm{VO}_{2 \max } /$ body mass ( $\left.\mathrm{mL} / \mathrm{kg} / \mathrm{min}\right)$ & $47.6 \pm 7.6$ & 29 & $47.5 \pm 7.3$ & 13 & $43.5 \pm 8.4$ & 30 & $43.4 \pm 8.9$ & 15 \\
\hline $\mathrm{VO}_{2 \max } / \mathrm{LBM}(\mathrm{mL} / \mathrm{kg} / \mathrm{min})$ & $63.6 \pm 12.2$ & 29 & $66.1 \pm 9.8$ & 13 & $56.5 \pm 8.7$ & 27 & $59.1 \pm 7.0$ & 15 \\
\hline $\mathrm{VO}_{2 \max } / \mathrm{LML}(\mathrm{mL} / \mathrm{kg} / \mathrm{min})$ & $192.5 \pm 40.9$ & 29 & $193.5 \pm 31.0$ & 13 & $172.4 \pm 25.5$ & 27 & $184.0 \pm 26.0$ & 15 \\
\hline
\end{tabular}

Subjects were grouped as GGN short $\left(G G N_{S}\right)$ if harboring repeat lengths of $\leq 23$ and $G G N$ long $(G G N L)$ if harboring repeat lengths of $>23$. Body composition statistical analysis was done with logarithmic data.

${ }^{*} P<0.05$ after accounting for $\mathrm{VO}_{2 \max }$ and MFO per $\mathrm{kg}$ of total lean mass.

${ }^{\dagger} P<0.05$ after adjusting for Tanner stage and $\mathrm{VO}_{2 \text { max }}$.

BMI, body mass index; LBM, lean body mass; LML, lean mass legs.

groups are reported in Tables 1 and 2, respectively. Longitudinal data, daily energy expenditure, basal fat oxidation, RMR, and MFO are reported in Table 3. The distribution of AR allele frequencies for CAG and GGN repeat numbers are illustrated in Fig. 1. The median CAG repeat length was 21 (range: 15-26), while the GGN median length was 23 (range: 14-27). The median
CAG values for short and long groups were 19 and 24, respectively. The corresponding mean values for the GGN groups were 22 and 24, for the $\mathrm{GGN}_{\mathrm{S}}$ and $\mathrm{GGN}_{\mathrm{L}}$, respectively.

At recruitment, subjects included in the follow-up had similar CAG and GGN length, as well as similar body composition and $\mathrm{VO}_{2 \max }$ compared with the subjects 


\section{Ponce-González et al.}

Table 3. Changes in body composition, resting metabolic rate, and maximal fat oxidation and depending on androgen receptor polymorphism

\begin{tabular}{|c|c|c|c|c|c|c|c|c|}
\hline & $\mathrm{CAG}_{\mathrm{S}}$ & $n$ & $C A G_{L}$ & $n$ & $\mathrm{GGN}_{\mathrm{S}}$ & $n$ & $\mathrm{GGN}_{\mathrm{L}}$ & $n$ \\
\hline \multicolumn{9}{|l|}{ Longitudinal data (changes) } \\
\hline Time elapsed between the measurements (years) & $13.73 \pm 0.57$ & 24 & $13.93 \pm 0.62$ & 21 & $13.82 \pm 0.61$ & 30 & $13.83 \pm 0.58$ & 15 \\
\hline Body fat mass accumulated (g/day) & $1.16 \pm 1.52$ & 23 & $1.61 \pm 2.23^{*}$ & 19 & $1.27 \pm 1.68$ & 27 & $1.53 \pm 2.21$ & 15 \\
\hline Trunk fat mass accumulated (g/day) & $0.81 \pm 0.95$ & 23 & $1.13 \pm 1.31$ & 19 & $0.88 \pm 1.07$ & 27 & $1.09 \pm 1.25$ & 15 \\
\hline Lean body mass accumulated (g/day) & $4.05 \pm 2.34$ & 23 & $5.77 \pm 2.38^{*}$ & 19 & $5.00 \pm 2.63$ & 27 & $4.52 \pm 2.26$ & 15 \\
\hline \multicolumn{9}{|l|}{ Energy expenditure tests } \\
\hline Energy expenditure (IPAQ) (Mets-h/week) & $72.66 \pm 69.53$ & 24 & $82.34 \pm 45.24$ & 21 & $77.40 \pm 68.07$ & 30 & $76.73 \pm 36.64$ & 15 \\
\hline Basal fat oxidation (mg/min) & $79.55 \pm 28.67$ & 24 & $88.46 \pm 32.10$ & 21 & $87.94 \pm 32.74$ & 30 & $75.25 \pm 23.47$ & 15 \\
\hline Basal fat oxidation/LBM (mL/kg/min) & $1.49 \pm 0.55$ & 23 & $1.42 \pm 0.63$ & 19 & $1.56 \pm 0.62$ & 27 & $1.29 \pm 0.46$ & 15 \\
\hline Basal fat oxidation/LML (mL/kg/min) & $4.58 \pm 1.74$ & 23 & $4.41 \pm 1.97$ & 19 & $4.78 \pm 1.97$ & 27 & $4.01 \pm 1.48$ & 15 \\
\hline Basal fat oxidation/LML· Htt ${ }^{-2}(\mathrm{~mL} / \mathrm{kg} / \mathrm{min})$ & $14.58 \pm 5.50$ & 23 & $13.96 \pm 6.07$ & 19 & $15.15 \pm 6.24$ & 27 & $12.77 \pm 4.36$ & 15 \\
\hline Resting metabolic rate $(\mathrm{kcal} / \mathrm{min})$ & $1.16 \pm 0.26$ & 24 & $1.36 \pm 0.31^{\star}$ & 21 & $1.29 \pm 0.32$ & 30 & $1.19 \pm 0.24$ & 15 \\
\hline Resting metabolic rate/LBM (kcal/kg/min) & $0.021 \pm 0.004$ & 23 & $0.021 \pm 0.005$ & 19 & $0.022 \pm 0.005$ & 27 & $0.020 \pm 0.005$ & 15 \\
\hline Maximal fat oxidation (mg/min) & $242.6 \pm 100.6$ & 24 & $332.8 \pm 117.1^{*}$ & 21 & $292.4 \pm 136.2$ & 30 & $269.1 \pm 62.3$ & 15 \\
\hline Maximal fat oxidation/LBM (mg/kg/min) & $4.47 \pm 1.48$ & 23 & $5.30 \pm 1.98$ & 19 & $5.02 \pm 2.02$ & 27 & $4.52 \pm 1.11$ & 15 \\
\hline Maximal fat oxidation/LML (mg/kg/min) & $13.62 \pm 4.50$ & 23 & $16.31 \pm 5.64$ & 19 & $15.25 \pm 5.85$ & 27 & $14.11 \pm 3.71$ & 15 \\
\hline Maximal fat oxidation $/ \mathrm{LML} \cdot \mathrm{Ht}^{-2}(\mathrm{mg} / \mathrm{kg} / \mathrm{min})$ & $43.62 \pm 14.67$ & 23 & $52.22 \pm 18.57$ & 19 & $48.75 \pm 19.43$ & 27 & $45.28 \pm 11.29$ & 15 \\
\hline
\end{tabular}

Subjects were grouped as $C A G$ short $\left(C A G_{S}\right)$ if harboring repeat lengths of $\leq 21$ and $C A G$ long $\left(C A G_{L}\right)$ if harboring repeat lengths of $>21$. The cut-off point for GGN short $\left(G G N_{S}\right)$ was $G G N$ repeat polymorphism $\leq 23$; otherwise, subjects were included in the GGN long $\left(G_{G N}\right)$ group.

${ }^{*} P<0.05$ without adjusting for any variable.

BMI, body mass index; LBM, lean body mass; LML, lean mass legs; Ht, height.
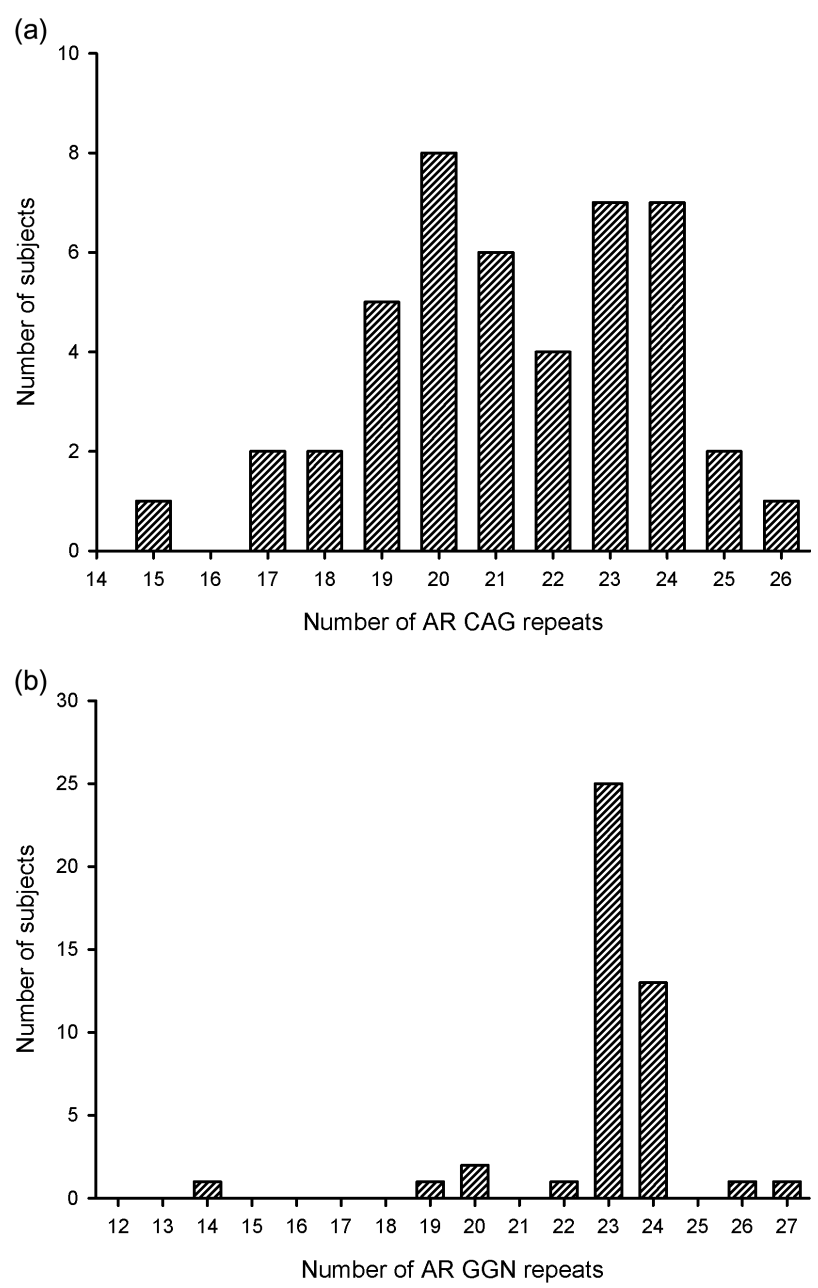

Fig. 1. Histogram representing the number of subjects with each (a) CAG and (b) GGN repeat number. excluded or lost, after accounting for age, height, and Tanner stage (data not shown).

$\mathrm{CAG}$, body composition, and $\mathrm{VO}_{2 \max }$ at recruitment

No statistically significant differences in age, body mass, height, lean body mass and cardiorespiratory fitness $\left(\mathrm{VO}_{2 \max }\right)$ were observed between $\mathrm{CAG}_{\mathrm{S}}$ and $\mathrm{CAG}_{\mathrm{L}}$ groups (Table 1). However, the BMI, percentage of body fat, whole body, and trunk fat mass were lower in the $\mathrm{CAG}_{\mathrm{S}}$ compared with the $\mathrm{CAG}_{\mathrm{L}}$ group (all $P<0.05$; Fig. 2(a)), even after accounting for pubertal status, age, and $\mathrm{VO}_{2 \max }(\mathrm{mL} / \mathrm{kg}$ of body mass $/ \mathrm{min})$ as covariates (Table 1).

Compared with the $\mathrm{CAG}_{\mathrm{S}}$, the $\mathrm{CAG}_{\mathrm{L}}$ group had greater total lean body mass, and lean mass in the lower and upper extremities after accounting for Tanner stage and age $(P<0.05)$.

GGN, body composition, and $\mathrm{VO}_{2 \max }$ at recruitment

No differences between $\mathrm{GGN}_{\mathrm{S}}$ and $\mathrm{GGN}_{\mathrm{L}}$ groups were observed in age, body mass, height, body composition, and $\mathrm{VO}_{2 \max }$ (Table 2). However, the percentage of body fat, and whole body and trunk fat mass were lower in GGN $_{\mathrm{S}}$ compared with $\mathrm{GGN}_{\mathrm{L}}$ after accounting for Tanner stage and $\mathrm{VO}_{2 \max }(\mathrm{mL} / \mathrm{kg}$ of body mass $/ \mathrm{min}$; all $P<0.05$; Fig. 2(a)).

CAG at adult age and longitudinal changes in body composition

No significant differences in age, height (Table 1), daily energy expenditure, and time elapsed between the two 
(a)

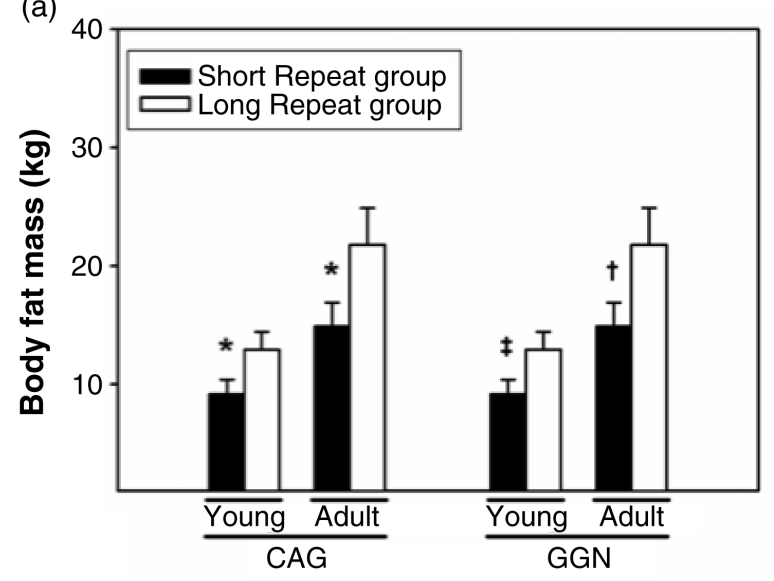

(b)

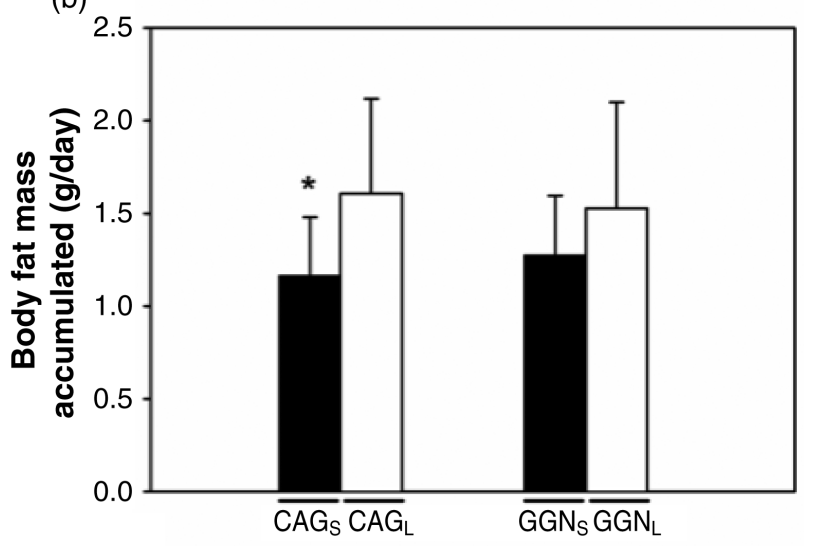

(c)

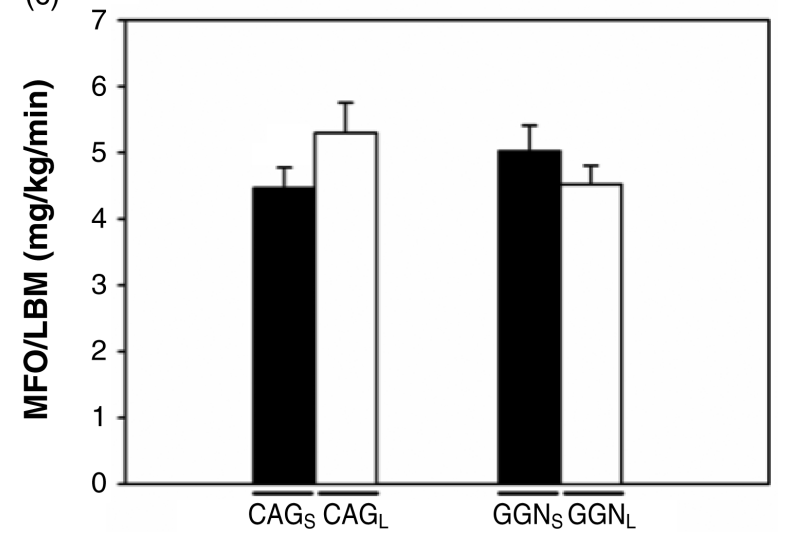

Fig. 2. Levels of (a) total body fat (kg) for CAG and GGN groups at young and adult age, (b) total body fat accumulation (g/day) for $\mathrm{CAG}_{\mathrm{S}}$ vs $\mathrm{CAG}_{\mathrm{L}}$, and $\mathrm{GGN}_{\mathrm{S}}$ vs $\mathrm{GGN}_{\mathrm{L}}$ groups and (c) maximal fat oxidation per $\mathrm{kg}$ of lean body mass $(\mathrm{mg} / \mathrm{kg} / \mathrm{min})$ for $\mathrm{CAG}_{\mathrm{S}} \mathrm{vs}_{\mathrm{C}} \mathrm{CAG}_{\mathrm{L}}$, and $\mathrm{GGN}_{\mathrm{S}}$ vs $\mathrm{GGN}_{\mathrm{L}}$ groups. $* P<0.05$ between short and long groups without adjusting for covariables; $\ddagger P<0.05$ between short and long groups after accounting for Tanner stage and $\mathrm{VO}_{2 \max } \dagger P<0.05$ between short and long groups after accounting for MFO per $\mathrm{kg}$ of total lean mass and $\mathrm{VO}_{2}$ max. Subjects were grouped as CAG short $\left(\mathrm{CAG}_{\mathrm{S}}\right)$ if harboring repeat lengths of $\leq 21$ and $C A G$ long $\left(\mathrm{CAG}_{\mathrm{L}}\right)$ if harboring repeat lengths of $>21$. The cutoff point for GGN short $\left(\mathrm{GGN}_{\mathrm{S}}\right)$ was GGN repeat polymorphism $\leq 23$; otherwise, subjects were included in the GGN long $\left(\mathrm{GGN}_{\mathrm{L}}\right)$ group. Plotted values correspond to raw unadjusted variables. measurements (Table 3) were observed between $\mathrm{CAG}_{\mathrm{s}}$ and $\mathrm{CAG}_{\mathrm{L}}$ groups. However, $\mathrm{CAG}_{\mathrm{L}}$ group accumulated $11.4 \pm 2.0 \mathrm{~kg}$ more total body mass and $2.3 \pm 3.4 \mathrm{~kg}$ more total body fat than the $\mathrm{CAG}_{\mathrm{S}}$ group during $13.7 \pm 0.6$ years of follow-up $(P=0.04$ and $P=0.03$, respectively; Fig. 2(b)). Moreover, $\mathrm{CAG}_{\mathrm{L}}$ showed a greater body mass, BMI, whole body, and trunk fat mass (Fig. 2(a)) compared with $\mathrm{CAG}_{\mathrm{S}}$ (all $P \leq 0.05$ ), even after accounting for age, total energy expenditure, $\mathrm{VO}_{2 \max }(\mathrm{mL} / \mathrm{kg}$ of body mass $/ \mathrm{min})$, and MFO per $\mathrm{kg}$ of total lean mass (Table 1).

Moreover, $\mathrm{CAG}_{\mathrm{L}}$ also showed greater lean mass in the lower $(15 \%)$ and upper (22\%) extremities, as well as greater total lean body mass $(16 \%)$ compared with $\mathrm{CAG}_{\mathrm{S}}$ (all $P<0.01$ ), even after accounting for age, total energy expenditure, and $\mathrm{VO}_{2 \max }(\mathrm{mL} / \mathrm{kg}$ of body mass $/ \mathrm{min}$; $P<0.05)$.

The MFO (absolute values) was greater in the $\mathrm{CAG}_{\mathrm{L}}$ than in the $\mathrm{CAG}_{\mathrm{s}}$ group $(P=0.01$; Fig. $2(\mathrm{c}))$, even after accounting for age and $\mathrm{VO}_{2 \max }(P<0.05)$. The RMR was $15 \%$ higher in the $\mathrm{CAG}_{\mathrm{L}}$ than $\mathrm{CAG}_{\mathrm{s}}$ group $(P=0.03)$. This difference, however, disappeared after accounting for age $(P=0.06)$, total lean mass $(P=0.30)$, or for both conjointly $(P=0.98)$.

GGN at adult age and longitudinal changes in body composition

No significant differences in age, height (Table 2), daily energy expenditure, and time elapsed between the two measurements were observed between $\mathrm{GGN}_{\mathrm{S}}$ and $\mathrm{GGN}_{\mathrm{L}}$ groups (Table 3). Both GGN groups had similar body composition, even after accounting for age, total energy expenditure, $\mathrm{VO}_{2 \max }(\mathrm{mL} / \mathrm{kg}$ of body mass $/ \mathrm{min})$ and MFO per $\mathrm{kg}$ of total lean mass. However, $\mathrm{GGN}_{\mathrm{L}}$ had a higher percentage of whole body and trunk fat mass than $\mathrm{GGN}_{\mathrm{S}}$ group after accounting for $\mathrm{VO}_{2 \max }(\mathrm{mL} / \mathrm{kg}$ of body mass/min) and MFO per $\mathrm{kg}$ of total lean mass (all $P<0.05$; Fig. 2(a)). The $\mathrm{GGN}_{\mathrm{S}}$ and $\mathrm{GGN}_{\mathrm{L}}$ subjects accumulated $6.4 \pm 8.3$ and $7.6 \pm 10.8 \mathrm{~kg}$ of whole body fat over $13.7 \pm 0.6$ years of follow-up (Fig. 2(b)). This difference in fat mass accumulation was not statistically significant $(P=0.67)$ even after accounting for the covariates.

\section{Correlations}

At adolescent and adult age, the logarithm of CAG repeats polymorphism was associated with the logarithm of percentage of body fat $(r=0.39, P=0.009$ and $r=0.3$, and $P=0.057$, respectively), logarithm of fat mass in the trunk region $(r=0.4, P=0.007$ and $r=0.41$, and $P=0.007$, respectively), and logarithm of body fat mass $(r=0.39, P=0.008$ and $r=0.38$, and $P=0.012$, respectively; Fig. 3). Moreover, there was an association between the logarithm of CAG repeats polymorphism and the changes in total lean body mass $(r=0.37$, 


\section{Ponce-González et al.}

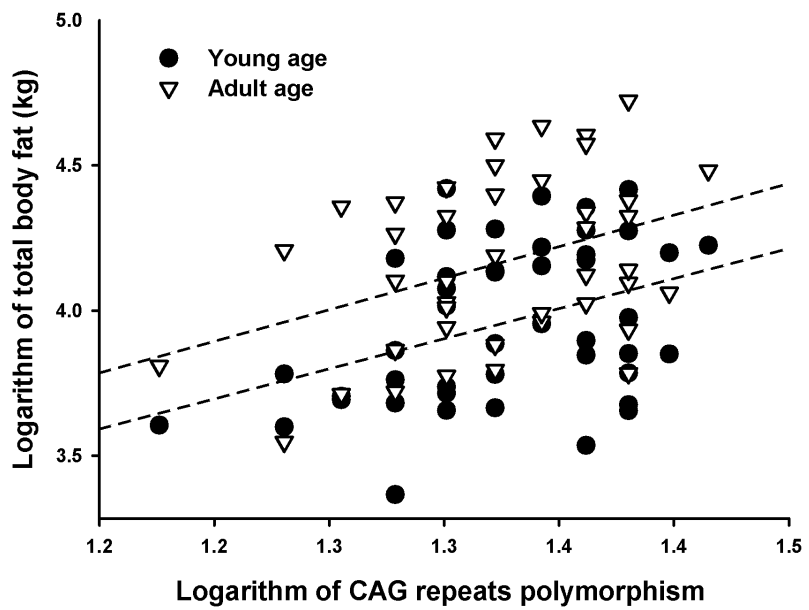

Fig. 3. Graphical display of the partial correlation between the logarithm of CAG repeat number with logarithm of total body fat at young $(r=0.39, P=0.008)$ and adult age $(r=0.38$, $P=0.012$ ). No significant differences were observed between the slopes of the straight lines.

$P=0.016)$. Logarithm of CAG repeats polymorphism was associated to the changes of $\mathrm{VO}_{2 \max }$ (absolute values; $r=0.34, P=0.03$ ).

\section{Discussion}

This study shows that the CAG repeat polymorphism may influence long-term changes in fat mass in humans. Young subjects with short CAG had lower whole body and trunk fat mass, and lower whole body lean mass compared with long CAG subjects. These differences in body composition were maintained until adult age. More importantly, we have shown that the $\mathrm{CAG}_{\mathrm{L}}$ is associated with increased whole body fat and lean mass gain with growth than the $\mathrm{CAG}_{\mathrm{S}}$ genotype.

In agreement with our results at adolescent age, Mouritsen et al. (2013) reported a greater body fat in $\mathrm{CAG}_{\mathrm{L}}$ compared with $\mathrm{CAG}_{\mathrm{S}}$ in 78 healthy Danish boys. Our results also agree with cross-sectional data obtained in adult men reporting that the CAG repeat polymorphism is positively associated with higher body fat (Zitzmann et al., 2003; Nielsen et al., 2010), and lean mass (Walsh et al., 2005). These associations could be due to enhanced androgen sensitivity, since it has been shown that short CAG repeats are associated to increased AR transactivation activity and stronger transcriptional potential (Chamberlain et al., 1994; Kazemi-Esfarjani et al., 1995; Beilin et al., 2000; Lee \& Chang, 2003). Thus, subjects with shorter CAG may have increased responsiveness to androgens and this may result in lower accumulation of fat mass over the years. In agreement with this interpretation, there is compelling evidence indicating that androgen administration reduces fat mass, while in men, reduced androgen levels are associated with lower lean mass and greater fat mass (Forbes et al., 1992; Mauras et al., 1998; Emmelot-Vonk et al., 2008). The observed increased lean mass in the $\mathrm{CAG}_{\mathrm{L}}$ group is likely due to the higher fat mass, since it has been shown in 24 lean men ( $21 \pm 2$ years) that fatfree mass increases $(2.8 \pm 1.5 \mathrm{~kg})$ with fat mass accumulation $(5.3 \pm 1.9 \mathrm{~kg})$ after 100 days of overfeeding (Bouchard et al., 1990), despite $0.9 \pm 0.6 \mathrm{nmol} / \mathrm{L}$ nonsignificant increase in testosterone levels (Pritchard et al., 1998). This was corroborated by the fact that the proportion between fat mass and lean mass was similar in CAGs and $\mathrm{CAG}_{\mathrm{L}}$ groups (data not shown).

The potential influence of GGN polymorphism on fat mass accumulation during growth has not been analyzed previously. As novelty, we have observed that a short GGN repeat length is associated with lower percentage of body fat, whole body and trunk fat mass in adolescents. However, at adult age, nonsignificant differences in fat mass or its regional distribution was observed between $\mathrm{GGN}_{\mathrm{S}}$ and $\mathrm{GGN}_{\mathrm{L}}$ groups. In agreement with our results, it has been shown that the length of the GGN tract is linearly and inversely associated with AR protein content in cell cultures (Ding et al., 2005), and longer GGN tracts result in a linearly reduced AR activity per cell (Ding et al., 2005). Therefore, this reduced activity of AR with longer GGN repeats could attenuate the anti-obesity effects of androgens, and effect that may be more notorious at young age, when the level of androgens are likely lower. Since this is the first study examining the influence of AR GGN repeat length on body composition at young age, no comparable data exist at the moment.

The results reported here concur with a recent study showing a positive association between GGN repeat length and adiposity in adult women, but not in men (Ponce-González et al., 2012). The lack of influence of GGN repeats on adiposity at adult age in men could be explained by the fact that in the present cohort, most men had GGN repeat lengths close to the median of the population. Therefore, future research should examine body composition and growth changes in subjects with extreme GGN repeat lengths.

Ara et al. (2011) reported that obese men have increased fat oxidation capacity compared with lean men. This finding agrees with our results, since $\mathrm{CAG}_{\mathrm{L}}$ group at adult age showed higher adiposity and lean mass, which could explain their greater RMR and MFO capacity compared with $\mathrm{CAG}_{\mathrm{s}}$ group. Moreover, GGN repeat polymorphism has been found to be associated positively with MFO at adult age in the present investigation.

It has been suggested that age, lean body mass, and $\mathrm{VO}_{2 \max }$ are determinant factors of fat oxidation capacity in humans (Nordby et al., 2006; Riddell et al., 2008; Solomon et al., 2008; Rosenkilde et al., 2015). Venables et al. (2005) reported in 300 subjects (143 women and $157 \mathrm{men})$ that estimated physical activity level, $\mathrm{VO}_{2 \max }$, and gender were significant predictors of MFO/FFM, together accounting for $12 \%$ of the variance. Moreover, 
normal-weight adolescents with high $\mathrm{VO}_{2 \max }$ (pertaining to the fourth quartile of $\mathrm{VO}_{2 \max }$ ) have lower risk of becoming overweight 4-6 years later (OR: 0.40) compared with the subjects in the first quartile of $\mathrm{VO}_{2 \max }$ (Savva et al., 2014). Despite the latter, a recent study has shown that a $7 \%$ increase of $\mathrm{VO}_{2 \max }$ elicited by highintensity training was not associated to increased maximal fat oxidation capacity (Larsen et al., 2015). However, in the present investigation, CAG groups showed similar age, physical activity levels, and relative $\mathrm{VO}_{2 \max }$ implying that the differences in fat mass accumulation between $\mathrm{CAG}_{\mathrm{S}}$ and $\mathrm{CAG}_{\mathrm{L}}$ cannot be attributed to these factors.

\section{Limitations}

The main limitation of this study is the small number of subjects having short or long AR repeat polymorphisms that were included in the longitudinal analysis. This was due to some subjects starting smoking, while others were lost because of residence changes or refusal to follow-up tests. Despite this limitation, our conclusions are solid since they rely on the assessment of multiple factors influencing fat mass accumulation such as physical fitness and maximal fat oxidation and are based on a long follow-up period.

We took special care to control for confounding variables such as RMR, maximal fat oxidation capacity normalized to lean mass, and $\mathrm{VO}_{2 \max }$. However, we could not account for other confounders like diet and alternative genetic factors. Since only 45 from 128 boys were assessed 14 years later, we cannot rule out a potential selection bias. However, this is unlikely since the genotype and phenotype of the subjects remaining in the study was similar to that of the subjects excluded or lost to follow-up.

In conclusion, androgen receptor CAG and GGN repeat polymorphisms influence fat mass and its regional distribution in healthy male adolescents. In addition, the CAG repeat polymorphism also influences fat accumulation during growth from the adolescence to the adultness. The association between AR CAG polymorphism and lean mass is likely due to the increased body weight, since it was mostly explained by increased lean mass in the lower extremities.

\section{Perspectives}

Fat mass accumulation is in part determined by genetic factors. Androgens are important regulators of fat and muscle mass. Here, we have shown that genetic variance in genes encoding for the androgen receptor may influence body composition and fat mass accumulation. This association between AR polymorphism and fat mass accumulation has escaped detection by genome-wide association studies (GWAS) because GWAS cannot detect this type of genetic variation. Future studies with humanized rodents expressing different length variants of AR could establish the relevance that AR polymorphism has for fat mass gain over time.

Key words: AR CAG polymorphisms, AR GGN polymorphisms, adolescent, fat mass.

\section{Acknowledgements}

The authors thank José Navarro de Tuero for his excellent technical assistance. This study was supported by Ministerio de Educación y Ciencia (DEP2006-56076-C06-04/ACTI) and FEDER, Gobierno de Canarias (PI2005/177), Proyecto Interreg IIIB BIOPOLIS, Fundación del Instituto Canario de Investigación del Cáncer (FICIC), Cabildo de Gran Canaria, Cabildo de Tenerife and La Caja de Canarias, and Proyecto Estructurante "Integración de los grupos de investigación en Ciencias de la Salud," ULPGC, Gobierno de Canarias (ULPAPD-08/01-4). All financial sources have been reported.

\section{References}

Achten J, Gleeson M, Jeukendrup AE. Determination of the exercise intensity that elicits maximal fat oxidation. Med Sci Sports Exerc 2002: 34: 92-97.

Ara I, Larsen S, Stallknecht B, Guerra B, Morales-Alamo D, Andersen JL, Ponce-González JG, Guadalupe-Grau A, Galbo H, Calbet JA, Helge JW. Normal mitochondrial function and increased fat oxidation capacity in leg and arm muscles in obese humans. Int $\mathrm{J}$ Obes (Lond) 2011: 35: 99-108.

Beilin J, Ball EM, Favaloro JM, Zajac JD. Effect of the androgen receptor CAG repeat polymorphism on transcriptional activity: specificity in prostate and non-prostate cell lines. J Mol Endocrinol 2000: 25: 85-96.
Bouchard C, Tremblay A, Despres JP, Nadeau A, Lupien PJ, Theriault G, Dussault J, Moorjani S, Pinault S, Fournier G. The response to long-term overfeeding in identical twins. N Engl J Med 1990: 322: 1477-1482.

Chamberlain NL, Driver ED, Miesfeld RL. The length and location of CAG trinucleotide repeats in the androgen receptor $\mathrm{N}$-terminal domain affect transactivation function. Nucleic Acids Res 1994: 22: 3181-3186.

Ding D, Xu L, Menon M, Reddy GP, Barrack ER. Effect of GGC (glycine) repeat length polymorphism in the human androgen receptor on androgen action. Prostate 2005: 62: 133-139.

Emmelot-Vonk MH, Verhaar HJ, Nakhai Pour HR, Aleman A, Lock TM,
Bosch JL, Grobbee DE, van der Schouw YT. Effect of testosterone supplementation on functional mobility, cognition, and other parameters in older men: a randomized controlled trial. JAMA 2008: 299: 39-52.

Forbes GB, Porta CR, Herr BE, Griggs RC. Sequence of changes in body composition induced by testosterone and reversal of changes after drug is stopped. JAMA 1992: 267: 397-399.

Frayn KN. Calculation of substrate oxidation rates in vivo from gaseous exchange. J Appl Physiol 1983: 55: 628-634.

Guadalupe-Grau A, Rodriguez-Gonzalez FG, Dorado C, Olmedillas H, Fuentes T, Perez-Gomez J, Delgado-Guerra S, Vicente-Rodriguez G, Ara I, Guerra B, 


\section{Ponce-González et al.}

Arteaga-Ortiz R, Calbet JA, Diaz-Chico BN. Androgen receptor gene polymorphisms lean mass and performance in young men. Br J Sports Med 2011: 45: 95-100.

Gustafson DR, Wen MJ, Koppanati BM. Androgen receptor gene repeats and indices of obesity in older adults. Int $\mathrm{J}$ Obes Relat Metab Disord 2003: 27: 75-81.

Hickey T, Chandy A, Norman RJ. The androgen receptor CAG repeat polymorphism and $\mathrm{x}$-chromosome inactivation in Australian Caucasian women with infertility related to polycystic ovary syndrome. J Clin Endocrinol Metab 2002: 87: 161-165.

Host C, Gormsen LC, Christensen B, Jessen N, Hougaard DM, Christiansen JS, Pedersen SB, Jensen MD, Nielsen $\mathrm{S}$, Gravholt $\mathrm{CH}$. Independent effects of testosterone on lipid oxidation and VLDL-TG production: a randomized, double-blind, placebo-controlled, crossover study. Diabetes 2013: 62: 1409-1416.

Kazemi-Esfarjani P, Trifiro MA, Pinsky L. Evidence for a repressive function of the long polyglutamine tract in the human androgen receptor: possible pathogenetic relevance for the (CAG)n-expanded neuronopathies. Hum Mol Genet 1995: 4: 523-527.

Kim J, Wang Z, Heymsfield SB, Baumgartner RN, Gallagher D. Total-body skeletal muscle mass: estimation by a new dual-energy x-ray absorptiometry method. Am J Clin Nutr 2002: 76: 378-383.

Larsen S, Danielsen JH, Sondergard SD, Sogaard D, Vigelsoe A, Dybboe R, Skaaby S, Dela F, Helge JW. The effect of high-intensity training on mitochondrial fat oxidation in skeletal muscle and subcutaneous adipose tissue. Scand J Med Sci Sports 2015: 25: e59-e69.

Lee DK, Chang C. Endocrine mechanisms of disease: expression and degradation of androgen receptor: mechanism and clinical implication. J Clin Endocrinol Metab 2003: 88: 4043-4054.

Lietzke MH. Relation between weightlifting totals and body weight. Science 1956: 124: 486-487.

Mauras N, Hayes V, Welch S, Rini A, Helgeson K, Dokler M, Veldhuis JD, Urban RJ. Testosterone deficiency in young men: marked alterations in whole body protein kinetics, strength, and adiposity. J Clin Endocrinol Metab 1998: 83: 1886-1892.

Mouritsen A, Hagen CP, Sorensen K, Aksglaede L, Mieritz MG, Main KM, Almstrup K, Rajpert-De Meyts E, Juul A. Androgen receptor CAG repeat length is associated with body fat and serum SHBG in boys: a prospective cohort study. J Clin Endocrinol Metab 2013: 98: E605-E609.

Nielsen TL, Hagen C, Wraae K, Bathum L, Larsen R, Brixen K, Andersen M. The impact of the CAG repeat polymorphism of the androgen receptor gene on muscle and adipose tissues in 20-29-year-old Danish men: Odense Androgen Study. Eur J Endocrinol 2010: 162: 795-804.

Nordby P, Saltin B, Helge JW. Whole-body fat oxidation determined by graded exercise and indirect calorimetry: a role for muscle oxidative capacity? Scand J Med Sci Sports 2006: 16: 209-214.

O'Reilly MW, House PJ, Tomlinson JW. Understanding androgen action in adipose tissue. J Steroid Biochem Mol Biol 2014: 143: 277-284.

Perez-Gomez J, Olmedillas H, Delgado-Guerra S, Royo IA, Vicente-Rodriguez G, Ortiz RA, Chavarren J, Calbet JA. Effects of weight lifting training combined with plyometric exercises on physical fitness, body composition, and knee extension velocity during kicking in football. Appl Physiol Nutr Metab 2008: 33: 501-510.

Ponce-González JG, Guadalupe-Grau A, Rodriguez-Gonzalez FG, Dorado C, Olmedillas H, Fuentes T, Rodriguez-Garcia L, Diaz-Chico BN, Calbet JA. Androgen receptor gene polymorphisms and the fat-bone axis in young men and women. J Androl 2012: 33: 644-650.

Pritchard J, Despres JP, Gagnon J, Tchernof A, Nadeau A, Tremblay A, Bouchard C. Plasma adrenal, gonadal, and conjugated steroids before and after long-term overfeeding in identical twins. J Clin Endocrinol Metab 1998: 83: 3277-3284.

Riddell MC, Jamnik VK, Iscoe KE, Timmons BW, Gledhill N. Fat oxidation rate and the exercise intensity that elicits maximal fat oxidation decreases with pubertal status in young male subjects. J Appl Physiol (1985) 2008: 105: 742-748.

Rodriguez-Gonzalez G, Ramirez-Moreno R, Perez P, Bilbao C, Lopez-Rios L, Diaz-Chico JC, Lara PC, Serra-Majem L, Chirino R, Diaz-Chico BN. The GGN and CAG repeat polymorphisms in the exon-1 of the androgen receptor gene are, respectively, associated with insulin resistance in men and with dyslipidemia in women. J Steroid Biochem Mol Biol 2009: 113: 202-208.

Roman-Viñas B, Serra-Majem L, Hagströmer M, Ribas-Barba L, Sjöström M, Segura-Cardona R.
International physical activity questionnaire: reliability and validity in a Spanish population. Eur J Sport Sci 2010: 10: 297-304.

Rosenkilde M, Reichkendler MH, Auerbach P, Bonne TC, Sjodin A, Ploug T, Stallknecht BM. Changes in peak fat oxidation in response to different doses of endurance training. Scand J Med Sci Sports 2015: 25: 41-52.

Savva SC, Tornaritis MJ, Kolokotroni O, Chadjigeorgiou C, Kourides Y, Karpathios T, Yiallouros PK. High cardiorespiratory fitness is inversely associated with incidence of overweight in adolescence: a longitudinal study. Scand J Med Sci Sports 2014: 24: 982-989.

Solomon TP, Marchetti CM, Krishnan RK, Gonzalez F, Kirwan JP. Effects of aging on basal fat oxidation in obese humans. Metabolism 2008: 57: 1141-1147.

Stanworth RD, Kapoor D, Channer KS, Jones TH. Androgen receptor CAG repeat polymorphism is associated with serum testosterone levels, obesity and serum leptin in men with type 2 diabetes. Eur J Endocrinol 2008: 159: 739-746.

Venables MC, Achten J, Jeukendrup AE. Determinants of fat oxidation during exercise in healthy men and women: a cross-sectional study. J Appl Physiol 2005: 98: 160-167.

Vicente-Rodriguez G, Ara I, Perez-Gomez J, Serrano-Sanchez JA, Dorado C, Calbet JA. High femoral bone mineral density accretion in prepubertal soccer players. Med Sci Sports Exerc 2004: 36: 1789-1795.

Voorhoeve PG, van Mechelen W, Uitterlinden AG,

Delemarre-van de Waal HA, Lamberts SW. Androgen receptor gene CAG repeat polymorphism in longitudinal height and body composition in children and adolescents. Clin Endocrinol (Oxf) 2011: 74: 732-735.

Walsh S, Zmuda JM, Cauley JA, Shea PR, Metter EJ, Hurley BF, Ferrell RE, Roth SM. Androgen receptor CAG repeat polymorphism is associated with fat-free mass in men. J Appl Physiol (1985) 2005: 98: 132-137.

Zitzmann M. Pharmacogenetics of testosterone replacement therapy. Pharmacogenomics 2009: 10: 1341-1349.

Zitzmann M, Gromoll J, von Eckardstein A, Nieschlag E. The CAG repeat polymorphism in the androgen receptor gene modulates body fat mass and serum concentrations of leptin and insulin in men. Diabetologia 2003: 46: 31-39. 